\title{
Matrix Extension with Fitness for Purpose and Stability Assessment of DHA and Additional Fatty Acids in Individual Whole Chicken Eggs
}

\author{
Gerald Patrick Dillon ${ }^{*}{ }^{\circledR}$, Alexandros Yiannikouris ${ }^{2}{ }^{\circ}$, Walter Brandl ${ }^{3}$, \\ Cathy Cardinall ${ }^{3}$, Wendy Yuan ${ }^{3}$, Colm Anthony Moran 4 (i) \\ ${ }^{1}$ Regulatory Affairs Department, Alltech Ireland, Dunboyne, Ireland \\ ${ }^{2}$ Research Department, Alltech Inc., Nicholasville, USA \\ ${ }^{3}$ Analytical Chemistry Department, Mérieux NutriSciences, Burnaby, Canada \\ ${ }^{4}$ Regulatory Affairs Department, Alltech SARL, Vire, France \\ Email: *gdillon@alltech.com
}

How to cite this paper: Dillon, G.P., Yiannikouris, A., Brandl, W., Cardinall, C., Yuan, W. and Moran, C.A. (2019) Matrix Extension with Fitness for Purpose and Stability Assessment of DHA and Additional Fatty Acids in Individual Whole Chicken Eggs. Food and Nutrition Sciences, 10, 517-532.

https://doi.org/10.4236/fns.2019.105038

Received: April 5, 2019

Accepted: May 13, 2019

Published: May 16, 2019

Copyright $\odot 2019$ by author(s) and Scientific Research Publishing Inc. This work is licensed under the Creative Commons Attribution International License (CC BY 4.0).

http://creativecommons.org/licenses/by/4.0/

\section{(c) (i) Open Access}

\begin{abstract}
The consumption of long chain polyunsaturated fatty acids (LC-PUFA) is associated with several human health benefits. Most notable of these LC-PUFA is docosahexaenoic acid (DHA $\mathrm{C}_{22: 6}$ ) whose inclusion is considered essential for optimum human health. Biofortification of common foods such as eggs with DHA has emerged as a specific approach to increase the intake of DHA in human populations. This can be achieved by supplementing poultry rations with feeds like microalgae or fish oil that are rich in DHA, which results in an increased uptake in the egg. Gas chromatography with flame ionization detection (GC-FID) is the method of choice when analyzing food such as eggs for DHA and other fatty acids. For regulatory studies it is desirable to demonstrate that the method is specifically suitable for the analysis of DHA and fatty acids in eggs. The purpose of this paper is to further extend the scope of the AOAC 996.06 methodology examined in the paper by Dillon et al., and to demonstrate the fitness for purpose of the method by examining specific validation parameters. It is a further objective to investigate the stability of DHA and other fatty acids of short and long timepoints. A validation of the method for the determination of DHA and three other fatty acids in eggs is thus presented.
\end{abstract}

\section{Keywords}

DHA, GC-FID, Fatty Acids, Analytical Method, Fitness for Purpose, Aurantiochytrium limacinum 


\section{Introduction}

An increased consumption of long-chain polyunsaturated fatty acids (LC-PUFA) in the human diet can be related to several health benefits including improved cognitive and cardiovascular function and immune health [1] [2] [3]. Among the group of LC-PUFA compounds, docosahexaenoic acid (DHA) is perhaps the best well known and researched and its inclusion in diets for optimum health has been well publicised [4] [5] [6]. Despite this, DHA intake remains low in many countries, particularly those where Western diets are prevalent [7] [8] [9]. The biofortification of common foods with DHA and other LC-PUFA is seen as a key approach by which to seamlessly boost consumption of these essential nutrients in human populations [3] [10]. DHA intake for example, can be increased in household foods, such as chicken eggs, by supplementing poultry dietary rations with feeds like microalgae or fish oil which are rich in DHA [11] [12] [13] [14].

Gas chromatography with flame ionization detection (GC-FID) has been established as the principle technique for analyzing fatty acids in foods, with the original method of fatty acids extraction and methylation to yield methyl ester derivatives being described by Folch et al. [15]. The method has been referenced in several publications in the analysis of DHA and fatty acids in eggs [11] [16]. In addition, variations of the method have been examined with a view to further developing the method in the analysis of eggs [17] [18]. Whilst the methodology has been widely investigated, there is a need for the method to be thoroughly validated to demonstrate to fitness for purpose in analyzing eggs for regulatory studies, for example in the analysis of fatty acids profiles, assessing egg enrichment studies and gaining an understanding of the efficacy of feed ingredients for the purpose of enriching chicken eggs.

The purpose of this paper therefore is to further extend the scope of the AOAC 996.06 methodology as examined in the paper by Dillon et al., [19] to include this additional matrix. The method was further applied to assess the stability of DHA and other fatty acids in the eggs over a range of timepoints. The parameters examined during the validation study included; linearity and range, the limit of detection (LOD) and limit of quantification (LOQ), accuracy, repeatability, inter-analyst reproducibility and specificity. Stability experiments were conducted samples of extracted egg after 2, 24 and 48 hours at room temperature; the stability of freeze-dried egg samples spiked with various concentrations of fatty acids was assessed after storage at $<-16^{\circ} \mathrm{C}$ for periods of $0,2,4,8,12,16$, 20 and 26 weeks and a freeze/thaw study over four cycles were conducted.

\section{Materials and Methods}

\subsection{Instrumentation and Chemicals $\&$ Reagents}

The procedure employed for the analysis of DHA and fatty acids in eggs followed the same analytical method as outline in the paper by Dillon et al., 2019. This includes the main chemicals, reagents and instrumentation used as well as 
the extraction of fat and methylation of extracts. Difference to sample and standard preparation are further noted herein.

In brief, the experiments were performed at Mérieux NutriSciences (Burnaby, Canada) and were performed on an Agilent 6890N gas chromatograph (Agilent, Ontario, Canada) equipped with a hydrogen FID and an Agilent 7683 autosampler (Agilent, Ontario, Canada). Solvents and reagents were sourced from Fisher Scientific (Ontario, Canada). These included diethyl ether, petroleum ether, water (HPLC grade), ethanol 95\%, chloroform, toluene, hexane and methanol. Boron trifluoride, $7 \%$ was prepared by diluting boron fluoride $14 \%$ one to one with methanol. Hydrochloric acid, $8.3 \mathrm{~N}$ was prepared by adding $250 \mathrm{ml}$ of concentrated $\mathrm{HCl}(12 \mathrm{~N})$ to $110 \mathrm{ml}$ of deionized water. Pyrogallic acid was obtained from TCI America (Portland, USA).

The following fatty acid methyl ester standards were sourced from Nu-Chek-Prep Inc. (Minnesota, USA); methyl 4,7,10,13,16,19-docosahexaenoate (DHA C $22: 6$ ); methyl octanoate $\left(\mathrm{C}_{8: 0}\right)$; methyl tetradecanoate $\left(\mathrm{C}_{14: 0}\right)$; methyl heptadecanoate $\left(\mathrm{C}_{17: 0}\right)$; methyl hexadecanoate $\left(\mathrm{C}_{18: 0}\right)$; methyl trans 9-octadecenoate $\left(\mathrm{C}_{18: 1 \mathrm{~T}}\right)$; and methyl 13 docosenoate $\left(\mathrm{C}_{22: 1}\right.$ cis-13). In addition, the internal standard for sample extraction, 1,2,3-triundecanoylglycerol (common name: triundecanoin), the internal standard for calibration curve and QCs, methyl undecanoate and docosahexaenoic acid (DHA) were also all purchased from Nu-Chek-Prep Inc. (Minnesota, USA). The Reference material NIST SRM 3275-2 Anchovy Oil concentrate and the Quality control sample NIST 3290 (Dry Cat Food) were purchased from NIST (Gaithersburg, USA).

To examine the acceptability of the method, two commercially available reference materials were analyzed. Reference material NIST SRM 3275-2 Anchovy Oil concentrate was analyzed with each set performed during this study to verify the acceptability of the analytical set. The reference material contained $187 \pm 8$ $\mathrm{mg} / \mathrm{g}$ of DHA C $22: 6$. A quality control reference material NIST 3290 (Dry Cat Food) was analyzed with each set performed during this study to verify the complete hydrolysis and derivatization of fatty acid bound within the chicken eggs.

\subsection{Preparation of Calibration Standards, Internal Standards and Quality Control Standards}

The FAME stock solutions were prepared by taking a known quantity of each of the commercial standards and dissolving in hexane and making up to $10 \mathrm{ml}$ in a volumetric flask. A mixed FAME standard working solution with a final concentration of $40 \mathrm{mg} / \mathrm{ml}$ of each FAME was prepared by taking an aliquot of each FAME stock solution and making up to $10 \mathrm{ml}$ with hexane. A methyl undecanoate internal standard solution was prepared by taking $1 \mathrm{~g}$ of methyl undecanoate, dissolving in hexane and making up to $10 \mathrm{ml}$. Calibration FAME standard solutions were prepared at $0.3,0.75,1.5,3,7.50$ and $15 \mathrm{mg} / \mathrm{ml}$ by adding volumes of the mixed FAME standard working solution with $100 \mu \mathrm{l}$ of methyl undecanoate internal standard solution and making up to $2000 \mu \mathrm{l}$ with hexane. Standard solutions were stored at $<-16^{\circ} \mathrm{C}$ when not in use. 


\subsection{Preparation of Egg Sample}

Control (blank) chicken egg samples were purchased locally and were freeze-dried prior to extraction and analysis. Any samples that could not be freeze-dried immediately were stored at $\leq-16^{\circ} \mathrm{C}$ until freeze-drying could be completed. Samples were freeze dried in a VirTis Benchtop Pro Freeze Dryer (SP Scientific, Pennsylvania, USA) for 48 hours.

\section{Extraction of fat}

Control egg powder was thoroughly mixed to ensure a homogeneous sample was obtained. A $0.15 \pm 0.01 \mathrm{~g}$ sample of the powder was weighed into a Mojonnier flask. Pyrogallic acid $(100 \mathrm{mg}$ ) was added to the flask which was then fortified with $75 \mu \mathrm{l}$ of $40 \mathrm{mg} / \mathrm{ml}$ mixed FAME standard working solution. A $2 \mathrm{ml}$ aliquot of triundecanoin internal standard solution, a few boiling granules and 2 $\mathrm{ml}$ of ethanol was added, and the suspension was mixed. A $10 \mathrm{ml}$ aliquot of 8.3 $\mathrm{M}$ hydrochloric acid was added and the flask was placed in a $70^{\circ} \mathrm{C}-80^{\circ} \mathrm{C}$ water bath for one hour with periodic mixing before being cooled to $20^{\circ} \mathrm{C}$ and vortex-mixed for 15 seconds. Excess ethanol was added to rinse down the walls of the flask. A $25 \mathrm{ml}$ portion of diethyl ether was added to the flask, which was stoppered and shaken gently. A $25 \mathrm{ml}$ portion of petroleum ether was added, and the flask was again shaken and vortex-mixed for two minutes. The flask was centrifuged for five minutes at $600 \mathrm{rpm}$ to yield a clear supernatant, which was decanted into a round bottomed flask and evaporated using a rotary evaporator.

\section{Methylation}

The extracted fat residue was dissolved in a $3 \mathrm{ml}$ volume of chloroform and a further $3 \mathrm{ml}$ of diethyl ether was added. The resulting solution was placed into a $10 \mathrm{ml}$ glass tube. The round bottomed flask was washed with diethyl ether and the washings were added and the solution was evaporated to dryness under nitrogen at $40^{\circ} \mathrm{C}$. A $2 \mathrm{ml}$ volume of $7 \% \mathrm{BF} 3$ reagent and $1 \mathrm{ml}$ of toluene was added to the glass tube which was vortex-mixed for 30 seconds. The tube was sealed and heated in an oven for 1 hour at $100^{\circ} \mathrm{C}$ with shaking every ten minutes. The tube was allowed to cool to $20^{\circ} \mathrm{C}$ and $5 \mathrm{ml}$ of HPLC-grade water, $1 \mathrm{ml}$ hexane and $1 \mathrm{~g}$ sodium sulfate were added. The tube was capped and vortex-mixed for one minute and then centrifuged at $2000 \mathrm{rpm}$ for 3 minutes. The resulting clear supernatant was dried with sodium sulfate and injected into the GC-FID.

\section{GC-FID Conditions}

The GC system used a SP2560 $100 \mathrm{~cm}$ long capillary column with an internal diameter of $0.25 \mathrm{~mm}$ and a film thickness of $0.20 \mu \mathrm{m}$ (Supelco, Pennsylvania, USA). Helium was employed as a carrier gas and had an initial flow of 1.1 $\mathrm{ml} / \mathrm{min}$ and an average velocity of $19 \mathrm{~cm} / \mathrm{sec}$ at a pressure of $35.74 \mathrm{psi}$. Air and hydrogen were used for the FID with pressures of 60 and 40 psi respectively. The initial oven temperature was $100^{\circ} \mathrm{C}$ which was held for four minutes and then ramped up at a rate of $3^{\circ} \mathrm{C} / \mathrm{min}$ to $240^{\circ} \mathrm{C}$ and maintained for 19 minutes. The injector was employed in the split mode (200:1) at a temperature of $225^{\circ} \mathrm{C}$. The detector temperature was $285^{\circ} \mathrm{C}$. 


\subsection{Method Validation}

\section{Linearity}

A standard curve that covered the range of analytes and the range of concentrations of fatty acids in the samples was prepared to demonstrate linearity on the GC-FID. Linear regression, forced through the origin and with equal weighting, was applied to the peak area ratios plot for the construction of calibration curves plotting FAME:IS peak area ratios of the calibration standards against FAME concentrations and provided information on the slope, coefficient of determination, and intercept. Standards contained $\mathrm{C}_{8: 0}, \mathrm{C}_{14: 0} ; \mathrm{C}_{17: 0} ; \mathrm{C}_{18: 0} ; \mathrm{C}_{18: 1 \mathrm{~T}}$, $\mathrm{C}_{22: 1}$ cis-13 and $\mathrm{C}_{22: 6}$ FAMEs along with $\mathrm{C} 11: 0$ internal standard.

\section{Limit of Detection (LOD) and Limit of Quantification (LOQ)}

The LOD and LOQ of the method were established for DHA $\mathrm{C}_{22: 6}$ by analyzing the endogenous quantity of DHA in a freeze-dried blank egg sample which was analyzed in ten replicates. The LOD of the method was determined as three times the standard deviation, whilst the LOD was deemed to be ten times the standard deviation.

\section{Accuracy}

The blank matrix sample, i.e. whole chicken egg composite, was spiked with $\mathrm{C}_{14: 0}, \mathrm{C}_{17: 0}, \mathrm{C}_{18: 0}$ and $\mathrm{C}_{22: 6}$ in FAME form at three levels: $0.1 \%, 0.25 \%$ and $0.4 \%$ $(w / v)$. All four analytes have endogenous levels in the blank matrix, which was extracted and analyzed in triplicate. The average of the endogenous levels found in the blank sample was subtracted from the final concentration prior to the spike recoveries being calculated.

\section{Repeatability}

The freeze-dried whole chicken egg composite sample was analyzed in triplicate by the first analyst in three separate analysis sets producing a total of nine results. In addition, the samples were analyzed in triplicate by the second analyst, for a total of three results. The mean, standard deviation and Relative Standard Deviation (\%RSD) were determined for results from both analysts, and the relative difference between the first and second analyst were compared. The acceptable criteria for $\%$ RSD was $<10 \%$.

\section{Specificity}

To determine the identity of the FAME analyzed in the study, each of the seven standards were analyzed individually and their retention times were recorded.

\section{Reference Materials}

To examine the acceptability of the method, two commercially available reference materials were analyzed. Reference material NIST SRM 3275-2 Anchovy Oil concentrate was analyzed with each set performed during this study to verify the acceptability of the analytical set. The reference material contains $187 \pm 8$ $\mathrm{mg} / \mathrm{g}$ of DHA C $22: 6$. A quality control reference material NIST 3290 (Dry Cat Food) was analyzed with each set performed during this study to verify the complete hydrolysis and derivatization of fatty acid bound within the Chicken Eggs. The results for the following analytes (Total fat, $\mathrm{C}_{14: 0}, \mathrm{C}_{16: 0}, \mathrm{C}_{18: 0}, \mathrm{C}_{18: 1 \mathrm{C}}, \mathrm{C}_{18: 1}$, 
$\mathrm{C}_{18: 2 \mathrm{C}}, \mathrm{C}_{18: 3}, \mathrm{C}_{20: 5}, \mathrm{C}_{22: 5}$ and $\left.\mathrm{C}_{22: 6}\right)$ were within three standard deviations of the established mean.

\section{Inter-analyst reproducibility}

To demonstrate the inter-analyst reproducibility and the inter-analyst repeatability, a second analyst repeated portions of the validation and the results were compared.

\subsection{Stability}

The following experiments were conducted over the course of the study to examine the stability of solutions and analytes; 1) the stability of the FAME stock solutions stored at $<-16^{\circ} \mathrm{C}$ over six months; 2 ) the calibration FAME standard solutions on the autosampler over the course of each analytical sequence; 3 ) the short-term stability testing was carried out on chicken egg extracts prepared during the accuracy study at room temperature to examine the shelf life of the extracted analytes during the testing procedure. Each matrix extract was spiked at three different concentration levels, $0.1 \%(\mathrm{w} / \mathrm{v}), 0.25 \%(\mathrm{w} / \mathrm{v})$ and $0.4 \%(\mathrm{w} / \mathrm{v})$. Three aliquots for each of the three levels, and therefore a total of nine aliquots of each chicken matrix, were examined. The extracts were analysed at 2, 24 and 48 hours.; 4) Long term stability testing was carried out on the freeze-dried and stored egg, to evaluate the stability of the analytes and egg matrix during the anticipated storage time of the samples. The samples were weighed and spiked appropriately (three experimental replicates spiked at three concentration levels $0.1 \%(\mathrm{w} / \mathrm{v}), 0.25 \%(\mathrm{w} / \mathrm{v})$ and $0.4 \%(\mathrm{w} / \mathrm{v}))$, prior to freeze-drying. After the spiked eggs were dried, they were stored frozen $\left(\leq-16^{\circ} \mathrm{C}\right)$ until the testing date. The long-term stability samples were analyzed at 0, 4, 8, 12, 16, 20 and 26 weeks. 5) the freeze and thaw stability was conducted over the course of four cycles. Freezing was established at $<-16^{\circ} \mathrm{C}$ overnight and thawing took place at room temperature for more than two hours. Initial analysis after one freeze-thaw cycle established the baseline measurement. Sample aliquots were tested after each freeze-thaw cycle for four cycles.

\section{Results}

\section{Linearity}

The method was linear over the calibration range of $0.3 \mathrm{mg} / \mathrm{ml}$ to $15 \mathrm{mg} / \mathrm{ml}$ for all seven FAME analytes; $\mathrm{C}_{8: 0}, \mathrm{C}_{14: 0} ; \mathrm{C}_{17: 0} ; \mathrm{C}_{18: 0} ; \mathrm{C}_{18: 1 \mathrm{~T}}, \mathrm{C}_{22: 1}$ cis-13 and $\mathrm{C}_{22: 6}$

FAME. The coefficients of determination, $\mathrm{R}^{2}$, were found to range from 0.998 to 1.000 for the seven analytes within the acceptable criteria of $R^{2} \geq 0.990(R \geq$ 0.995). See results in Table 1.

\section{Limit of Detection (LOD) and Limit of Quantification (LOQ)}

To determine this method's LOD and LOQ for $\mathrm{C}_{22: 6}$ the blank egg matrix samples were analyzed in ten replicates. The standard deviation was determined to be $0.0068 \%$. The LOD, calculated as three times the Standard Deviation, is $0.02 \%$. The LOQ, calculated as ten times the Standard Deviation, is $0.07 \%$. See Table 2. 
Table 1. Correlation coefficients for fatty acid analysis of individual, whole chicken eggs (R).

\begin{tabular}{cccccccc}
\hline & \multicolumn{7}{c}{ Correlation Coefficient, $\mathrm{c}$} \\
\cline { 2 - 7 } ID & $\mathrm{C}_{8: 0}$ & $\mathrm{C}_{14: 0}$ & $\mathrm{C}_{17: 0}$ & $\mathrm{C}_{18: 0}$ & $\mathrm{C}_{18: 1 \text { trans }}$ & $\mathrm{C}_{22: 1 \text { cis 13 }}$ & $\mathrm{C}_{22: 6}$ \\
\hline Chicken Egg Spikes Day 1 & 1.000 & 1.000 & 1.000 & 1.000 & 1.000 & 1.000 & 1.000 \\
Chicken Egg Spikes Day 2 & 1.000 & 1.000 & 1.000 & 1.000 & 1.000 & 1.000 & 1.000 \\
LOD/LOQ & 1.000 & 1.000 & 1.000 & 1.000 & 1.000 & 1.000 & 1.000 \\
Short Term Stability & 1.000 & 1.000 & 1.000 & 1.000 & 1.000 & 0.999 & 1.000 \\
Long Term Stability & 0.999 & 1.000 & 1.000 & 1.000 & 1.000 & 0.999 & 1.000 \\
Second Analyst Spikes & 1.000 & 1.000 & 0.999 & 0.999 & 0.999 & 0.999 & 0.999 \\
Chicken Egg Spikes Day 3 & 1.000 & 0.999 & 0.998 & 0.998 & 0.999 & 0.998 & 0.998 \\
Freeze-Thaw study & 0.999 & 1.000 & 1.000 & 1.000 & 1.000 & 0.999 & 1.000 \\
\hline
\end{tabular}

Table 2. Limit of Detection (LOD) and Limit of Quantitation (LOQ) of docosahexaenoic acid (DHA) in individual, whole chicken eggs.

\begin{tabular}{ccc}
\hline Sample & DHA (\%) \\
\hline 1 & 0.498 \\
2 & 0.495 \\
3 & 0.492 \\
4 & 0.503 \\
5 & 0.498 \\
6 & 0.487 \\
7 & 0.478 \\
8 & 0.495 \\
9 & 0.493 \\
10 & 0.494 \\
Mean (\%) & 0.493 \\
Standard Deviation & 0.0068 \\
Relative Standard Deviation (\%) & 1.4 \\
LOD (\%) & 0.02 \\
LOQ (\%) & 0.07 \\
\hline
\end{tabular}

\section{Accuracy, repeatability and specificity}

The spike recoveries for the four monitored compounds were calculated and ranged from $91 \%$ to $110 \%$ which is within the acceptable range of $90 \%$ to $110 \%$. The mean of the recoveries ranged from $97 \%$ to $108 \%$. See Table 3 for the summary of accuracy results.

An example calculation for Day-1-Spike- $1, \mathrm{C}_{14: 0}$ at spiked at $0.1 \%$, is as follows:

$$
\begin{aligned}
\% \text { Recovery } & =\frac{(\text { Amt found in spike }- \text { Amt found in blank })}{\text { Amt spiked }} \times 100 \% \\
& =\frac{(1292.691-202.953)}{1000} \times 100 \% \\
& =109.0 \%
\end{aligned}
$$


Table 3. Accuracy (as measured by recovery\%) of select fatty acids spiked at 3 levels $(0.1 \%, 0.25 \%$ and $0.4 \%)$ in individual whole chicken eggs.

\begin{tabular}{|c|c|c|c|c|c|c|c|c|c|c|c|c|}
\hline \multirow{3}{*}{ Primary Analyst } & \multicolumn{12}{|c|}{ Recovery (\%) } \\
\hline & \multicolumn{4}{|c|}{ Spiked $0.1 \%$} & \multicolumn{4}{|c|}{ Spiked $0.25 \%$} & \multicolumn{4}{|c|}{ Spiked $0.4 \%$} \\
\hline & $\mathrm{C}_{14: 0}$ & $\mathrm{C}_{17: 0}$ & $\mathrm{C}_{18: 0}$ & $\mathrm{C}_{22: 6}$ & $\mathrm{C}_{14: 0}$ & $\mathrm{C}_{17: 0}$ & $\mathrm{C}_{18: 0}$ & $\mathrm{C}_{22: 6}$ & $\mathrm{C}_{14: 0}$ & $\mathrm{C}_{17: 0}$ & $\mathrm{C}_{18: 0}$ & $\mathrm{C}_{22: 6}$ \\
\hline Day 1-1 & 109 & 108 & 110 & 105 & 107 & 108 & 110 & 106 & 107 & 106 & 108 & 105 \\
\hline Day $1-2$ & 106 & 104 & 102 & 100 & 104 & 104 & 102 & 102 & 107 & 106 & 106 & 104 \\
\hline Day 1-3 & 109 & 110 & 110 & 108 & 108 & 107 & 105 & 104 & 106 & 105 & 105 & 103 \\
\hline Day 2-1 & 107 & 106 & 107 & 105 & 107 & 107 & 107 & 106 & 105 & 103 & 99 & 101 \\
\hline Day 2-2 & 109 & 109 & 110 & 108 & 109 & 110 & 110 & 109 & 108 & 106 & 103 & 104 \\
\hline Day 2-3 & 107 & 108 & 110 & 107 & 107 & 105 & 99 & 102 & 109 & 108 & 104 & 105 \\
\hline Day 3-1 & 100 & 102 & 109 & 100 & 107 & 108 & 106 & 102 & 108 & 108 & 101 & 102 \\
\hline Day 3-2 & 107 & 108 & 109 & 108 & 105 & 105 & 95 & 99 & 108 & 107 & 106 & 104 \\
\hline Day 3-3 & 99 & 100 & 107 & 98 & 105 & 105 & 95 & 99 & 106 & 106 & 107 & 103 \\
\hline Mean & 106 & 106 & 108 & 104 & 107 & 106 & 103 & 103 & 107 & 106 & 104 & 104 \\
\hline SD & 3.8 & 3.3 & 2.8 & 3.9 & 1.7 & 1.8 & 5.7 & 3.2 & 1.3 & 1.3 & 2.9 & 1.4 \\
\hline RSD (\%) & 3.6 & 3.1 & 2.6 & 3.8 & 1.6 & 1.7 & 5.6 & 3.1 & 1.2 & 1.2 & 2.8 & 1.3 \\
\hline $\begin{array}{c}\text { Secondary } \\
\text { Analyst }\end{array}$ & $\mathrm{C}_{14: 0}$ & $\mathrm{C}_{17: 0}$ & $\mathrm{C}_{18: 0}$ & $\mathrm{C}_{22: 6}$ & $\mathrm{C}_{14: 0}$ & $\mathrm{C}_{17: 0}$ & $\mathrm{C}_{18: 0}$ & $\mathrm{C}_{22: 6}$ & $\mathrm{C}_{14: 0}$ & $\mathrm{C}_{17: 0}$ & $\mathrm{C}_{18: 0}$ & $\mathrm{C}_{22: 6}$ \\
\hline Day 1-1 & 107 & 107 & 98 & 103 & 106 & 106 & 100 & 100 & 108 & 107 & 99 & 102 \\
\hline Day 1-2 & 99 & 100 & 100 & 95 & 104 & 103 & 91 & 97 & 107 & 108 & 105 & 104 \\
\hline Day 1-3 & 99 & 100 & 101 & 96 & 106 & 107 & 100 & 102 & 106 & 107 & 107 & 103 \\
\hline Mean & 101 & 102 & 100 & 98 & 105 & 105 & 97 & 100 & 107 & 107 & 104 & 103 \\
\hline SD & 4.6 & 4.1 & 1.8 & 4.6 & 1.1 & 2.1 & 5.7 & 2.8 & 0.9 & 0.5 & 4.1 & 1.1 \\
\hline RSD (\%) & 4.6 & 4.0 & 1.8 & 4.7 & 1.1 & 2 & 5.8 & 2.8 & 0.8 & 0.5 & 3.9 & 1.1 \\
\hline $\begin{array}{c}\text { Relative } \\
\text { Difference (\%) to } \\
\text { Primary Analyst }\end{array}$ & -4.2 & -3.4 & -8.1 & -6 & -1.6 & -1 & -6 & -3.3 & -0.1 & 0.8 & -0.6 & -0.6 \\
\hline
\end{tabular}

The samples were analyzed in triplicate over three separate analysis sets by the first analyst, giving a total of nine determinations. In order to assess the repeatability, the mean and standard deviation of the recoveries were calculated to determine the \%RSD. The \%RSD for chicken egg samples were within the acceptable range of $<10 \%$ RSD for DHA $\left(\mathrm{C}_{22: 6}\right)$ with results of $1.0 \%$ for the first analyst and $1.9 \%$ for the second analyst. A summary of the results can be found in Table 4 .

To assess the specificity, the retention times of each FAME standard were determined individually and in a mixed standards solution. A low-level spike was compared with a blank matrix chromatogram and demonstrates that the method distinguishes between the analytes of interest and other substances which might be present in the matrix. 
Table 4. Repeatability of fatty acids (\% RSD; $\mathrm{n}=9)$ in whole chicken egg extracts and determination of relative difference $(\% \mathrm{RD})$ between first and second analysts.

\begin{tabular}{|c|c|c|c|c|c|c|c|}
\hline \multirow[b]{2}{*}{ Fatty acid } & \multicolumn{3}{|c|}{ First analyst } & \multicolumn{3}{|c|}{ Second analyst } & \multirow{2}{*}{$\begin{array}{l}\text { \% RD First and } \\
\text { Second Analyst }\end{array}$} \\
\hline & $\begin{array}{l}\text { Mean } \mathrm{mg} / \mathrm{g} \\
\quad(\mathrm{n}=9)\end{array}$ & SD & $\%$ RSD & $\begin{array}{l}\text { Mean } \mathrm{mg} / \mathrm{g} \\
\quad(\mathrm{n}=3)\end{array}$ & SD & $\%$ RSD & \\
\hline $\mathrm{C}_{14: 0}$ & 0.0974 & 0.0011 & 1.16 & 0.0987 & 0.0012 & 1.1703 & 1.254 \\
\hline $\mathrm{C}_{14: 1}$ & 0.0142 & 0.0004 & 3.1005 & 0.0143 & 0.0015 & 10.657 & 0.781 \\
\hline $\mathrm{C}_{15: 0}$ & 0.028 & 0.0007 & 2.5254 & 0.028 & 0.0000 & 0.0000 & 0.000 \\
\hline $\mathrm{C}_{16: 0}$ & 8.4601 & 0.114 & 1.3478 & 8.6257 & 0.0746 & 0.8652 & 1.957 \\
\hline $\mathrm{C}_{16: 1 \mathrm{n} 7}$ & 0.7143 & 0.0086 & 1.2042 & 0.7263 & 0.0049 & 0.6791 & 1.68 \\
\hline $\mathrm{C}_{17: 0}$ & 0.0848 & 0.0048 & 5.6501 & 0.0807 & 0.0012 & 1.4314 & -4.849 \\
\hline $\mathrm{C}_{17: 1}$ & 0.0577 & 0.0007 & 1.2262 & 0.059 & 0.001 & 1.6949 & 2.312 \\
\hline $\mathrm{C}_{18: 0}$ & 2.7554 & 0.0413 & 1.5004 & 2.788 & 0.026 & 0.9326 & 1.181 \\
\hline $\mathrm{C}_{18: 1 \mathrm{~T}}$ & 0.0954 & 0.0024 & 2.4633 & 0.0957 & 0.0031 & 3.1934 & 0.233 \\
\hline $\mathrm{C}_{18: 1 \mathrm{n} 9}$ & 13.364 & 0.1874 & 1.4019 & 13.56 & 0.1153 & 0.8505 & 1.463 \\
\hline $\mathrm{C}_{18: \ln 7}$ & 0.636 & 0.012 & 1.8819 & 0.6777 & 0.0261 & 3.8518 & 6.551 \\
\hline $\mathrm{C}_{18: 2 \mathrm{n} 6}$ & 5.0456 & 0.0742 & 1.4703 & 5.1307 & 0.043 & 0.8389 & 1.687 \\
\hline $\mathrm{C}_{18: 3 \mathrm{n} 3}$ & 0.3512 & 0.0054 & 1.5318 & 0.3543 & 0.0031 & 0.8622 & 0.886 \\
\hline $\mathrm{C}_{18: 3 \mathrm{n} 6}$ & 0.0541 & 0.0015 & 2.8397 & 0.0553 & 0.0021 & 3.762 & 2.259 \\
\hline $\mathrm{C}_{20: 0}$ & 0.0118 & 0.0007 & 5.6604 & 0.0117 & 0.0006 & 4.9487 & -0.943 \\
\hline $\mathrm{C}_{20: 1 \mathrm{n} 9}$ & 0.1156 & 0.0017 & 1.5058 & 0.1163 & 0.0012 & 0.9926 & 0.673 \\
\hline $\mathrm{C}_{20: 2}$ & 0.0558 & 0.0025 & 4.5513 & 0.0543 & 0.0012 & 2.1252 & -2.59 \\
\hline $\mathrm{C}_{20: 3 \mathrm{n} 3}$ & 0.0074 & 0.0009 & 11.847 & 0.0077 & 0.0006 & 7.5307 & 2.985 \\
\hline $\mathrm{C}_{20: 3 \mathrm{n} 6}$ & 0.064 & 0.0005 & 0.7813 & 0.0647 & 0.0015 & 2.3622 & 1.042 \\
\hline $\mathrm{C}_{20: 4}$ & 0.6693 & 0.0105 & 1.5616 & 0.6753 & 0.0121 & 1.7851 & 0.896 \\
\hline $\mathrm{C}_{20: 5 \mathrm{n} 3}$ & 0.0079 & 0.0006 & 7.6174 & 0.0083 & 0.0006 & 6.9282 & 5.634 \\
\hline $\mathrm{C}_{22: 0}$ & 0.0126 & 0.0019 & 14.959 & 0.0147 & 0.0006 & 3.9365 & 16.814 \\
\hline $\mathrm{C}_{22: 5}$ & 0.0352 & 0.0012 & 3.4122 & 0.0357 & 0.0006 & 1.6187 & 1.262 \\
\hline $\mathrm{C}_{22: 6}$ & 0.5043 & 0.0053 & 1.0445 & 0.5133 & 0.0097 & 1.8921 & 1.785 \\
\hline $\mathrm{C}_{24: 1}$ & 0.0542 & 0.0051 & 9.484 & 0.052 & 0.0087 & 16.765 & -4.098 \\
\hline $\begin{array}{c}\sum \text { omega } 3 \\
(\%)\end{array}$ & 0.8709 & 0.0095 & 1.093 & 0.8837 & 0.0115 & 1.3018 & 1.467 \\
\hline $\begin{array}{c}\sum \text { omega } 6 \\
(\%)\end{array}$ & 5.0997 & 0.0749 & 1.4697 & 5.186 & 0.0451 & 0.8692 & 1.693 \\
\hline $\begin{array}{c}\sum \text { omega } 7 \\
(\%)\end{array}$ & 1.3503 & 0.0183 & 1.3554 & 1.404 & 0.0308 & 2.1941 & 3.974 \\
\hline $\begin{array}{c}\Sigma \text { omega } 9 \\
(\%)\end{array}$ & 13.479 & 0.1856 & 1.3772 & 13.677 & 0.121 & 0.8845 & 1.467 \\
\hline
\end{tabular}




\section{Reference Materials}

The results of the reference materials supported the suitability of the method in determining the fatty acid analytes. The reference material NIST SRM 3275-2 Anchovy Oil concentrate yielded results ranged from 173 to $183 \mathrm{mg} / \mathrm{g}$. These results are within the acceptable range of 2 standard deviations from the mean, which was determined to be 172 to $185 \mathrm{mg} / \mathrm{g}$. See Table 5.

The quality control sample NIST 3290 (Dry Cat Food) was analyzed with each set performed during this study to verify the complete hydrolysis and derivatization of fatty acid bound within the Chicken Eggs. The results for the following analytes (Total fat, $\mathrm{C}_{14: 0}, \mathrm{C}_{16: 0}, \mathrm{C}_{18: 0}, \mathrm{C}_{18: 1 \mathrm{C}}, \mathrm{C}_{18: 1}, \mathrm{C}_{18: 2 \mathrm{C}}, \mathrm{C}_{18: 3}, \mathrm{C}_{20: 5}, \mathrm{C}_{22: 5}$ and $\mathrm{C}_{22: 6}$ ) were within three standard deviations of the established mean. See Table 6.

\section{Inter-analyst Reproducibility}

To demonstrate the robustness and the inter-analyst reproducibility, a second

Table 5. Concentration of $\mathrm{C}_{22: 6}$ (DHA) in found in Reference Material (NIST SRM 3275-2 Anchovy Oil concentrate).

\begin{tabular}{cc}
\hline ID & $\mathrm{C}_{22: 6}(\mathrm{mg} / \mathrm{g})$ \\
\hline Chicken Egg Spikes Day 1 & 179 \\
Chicken Egg Spikes Day 2 & 177 \\
LOD/LOQ & 173 \\
Short Term Stability & 182 \\
Long Term Stability & 177 \\
Chicken Egg Spikes Day 4 & 183 \\
Freeze - Thaw study & 180 \\
Mean & 178.8 \\
SD & 3.32 \\
RSD of Primary Analyst (\%) & 1.86 \\
Acceptable Range & $172-185$ \\
Secondary Analyst Spikes & 181 \\
Relative Difference (\%) to Primary Analyst & 1.35
\end{tabular}

Where: Acceptable Range $=$ Mean $\pm 2 \times$ Standard Deviation (SD); RSD (\%) $=($ Mean of Response $/ \mathrm{SD}) *$ 100 ; Relative Difference $(\%)=\left[\left(\right.\right.$ Mean $_{2 \text { nd analyst }}-$ Mean $\left._{1 \text { st analyst }}\right) /$ Mean $\left._{1 \text { st analyst }}\right] * 100$.

Table 6. Concentration of fatty acids $(n=7)$ found in Quality Control Material (NIST 3290-Dry Cat Food) used in the verification of the hydrolysis and derivatization procedure.

\begin{tabular}{|c|c|c|c|c|c|c|c|c|c|c|}
\hline & $\mathrm{C}_{14: 0}$ & $\mathrm{C}_{16: 0}$ & $\mathrm{C}_{18: 0}$ & $\mathrm{C}_{18: 1 \text { cis }}$ & $\mathrm{C}_{18: 1}$ & $\mathrm{C}_{18: 2}$ & $\mathrm{C}_{18: 3}$ & $\mathrm{C}_{20: 5}$ & $\mathrm{C}_{22: 5}$ & $\mathrm{C}_{22: 6}$ \\
\hline Acceptable range & $0.740-1.62$ & $25.33-27.97$ & $6.52-7.42$ & $25.54-45.59$ & $1.94-2.17$ & $26.42-29.05$ & $1.51-1.67$ & $0.606-0.686$ & $0.121-0.145$ & $0.48-0.54$ \\
\hline Mean $(\mathrm{n}=7)$ & 1.18 & 26.65 & 6.97 & 35.56 & 2.06 & 27.73 & 1.59 & 0.646 & 0.133 & 0.509 \\
\hline SD & 0.15 & 0.44 & 0.15 & 3.34 & 0.04 & 0.44 & 0.03 & 0.01 & 0.004 & 0.01 \\
\hline$\%$ RSD & 12.4 & 1.65 & 2.16 & 9.4 & 1.83 & 1.58 & 1.72 & 2.07 & 3.01 & 2.02 \\
\hline
\end{tabular}

Where: Acceptable Range $=$ Mean $\pm 3 \times$ Standard Deviation $(\mathrm{SD}) ; \operatorname{RSD}(\%)=(\mathrm{SD} /$ Mean of Response $) * 100$. 
analyst repeated portions of the validation and the results were compared. The Reference Material results for the second analyst were within the acceptable range with results of 170 and $181 \mathrm{mg} / \mathrm{g}$ which meet the criteria of 2 standard deviations of the established mean. See Table 5. The results for the following analytes on the quality control sample for the second analyst were within three standard deviations of the established mean.

The egg samples were also analyzed by the second analyst. Results for DHA $\left(\mathrm{C}_{22: 6}\right)$ were found to be within three standard deviations of the established mean. The mean established by the first analyst for DHA was $0.504 \%$, with a standard deviation of $0.005 \%$. Calculating \pm 3 standard deviations around the mean, this equates to an acceptable range of $0.489 \%$ to $0.519 \%$. The second analyst had mean results of $0.513 \%$ for DHA, which is within the acceptable range (Table 4). The recoveries on the spiked matrix samples ranged between $91 \%$ and $108 \%$ for the second analyst, within the acceptable criteria of $90 \%$ to $110 \%$. See Table 3.

\subsection{Short and Long-Term Stability of Egg Samples}

\subsubsection{Stability of FAME Stock Solutions}

New stock solutions were compared against the original stock solutions which were prepared prior to use on experiments. The change of the seven fatty acid FAME analytes between the old stock solution and new stock solutions were determined to be between $-1.9 \%$ and $8 \%$ relative difference and showed stability for 207 days (over six months).

\subsubsection{Stability of Calibration FAME Standard Solutions}

Fresh calibration solutions were prepared for each analysis performed on the GC instrument autosampler. Repeated injections were performed at the start and end of the sequence to confirm stability over the course of the analysis. The calibration solutions at the end of the sequence ranged from $-5.9 \%$ to $3.5 \%$ relative error compared to the calibration solutions at the beginning of the sequence. This is within the acceptable range of $\pm 20 \%$ relative error.

\subsubsection{Short-Term Stability-Extracts}

Short term stability testing was carried out on egg extracts from the accuracy study at room temperature to account for the shelf life of the extracted analytes during the testing procedure. This involved spiking at three different concentration levels, $0.1 \%(\mathrm{w} / \mathrm{v}), 0.25 \%(\mathrm{w} / \mathrm{v})$ and $0.4 \%(\mathrm{w} / \mathrm{v})$. Three aliquots for each of the three levels were studied, for a total of nine aliquots. The extracts were analyzed at 2 hours, 24 hours and 48 hours. The relative error (\%) was calculated as the difference between the mean recovery at time $t$ and the mean recovery at time 0 ( 2 hours), divided by the mean recovery at time 0 , expressed as a percentage. The calculation formula can be found as a footnote on Table 8. The relative error (\%) was found to be within $\pm 20 \%$ relative error (ranging between $-6.4 \%$ to $2.9 \%$ ) compared to extracts from initial extraction ( $\mathrm{T}=0$ (2 hours)) for the parameters 
monitored: $\mathrm{C}_{14: 0}, \mathrm{C}_{17: 0}, \mathrm{C}_{18: 0}$ and $\mathrm{C}_{22: 6}$. The analytes were deemed to be stable at room temperature at the 2-hour, 24 hour and 48-hour mark. See Table 7.

\subsubsection{Long-Term Stability}

Long term stability testing was carried out on the freeze-dried and stored egg, to evaluate the stability of the analytes and egg matrix during the anticipated storage time of the samples. For the 4- and 8-week time frames, the stored samples were within $\pm 20 \%$ relative error (ranging between $-20 \%$ to $7.0 \%$ ) compared to extracts from initial extraction $(T=0)$ for the parameters monitored: $C_{14: 0}, C_{17: 0}$, $\mathrm{C}_{18: 0}$ and $\mathrm{C}_{22: 6}$. For the 12-week stability samples, however, the data for $\mathrm{C}_{18: 0}$ was outside the range of $\pm 20 \%$ relative error, with results of $-36 \%,-26 \%$ and $-20 \%$ for the $0.1 \%, 0.25 \%$ and $0.4 \%$ spiking levels, respectively. For 16, 20, and 26 weeks storage, results for $\mathrm{C}_{18: 0}$ remained outside the range of $\pm 20 \%$ relative error for the $0.1 \%$ spiking level only. Results for $\mathrm{C}_{18: 0}$ at the $0.25 \%$ and $0.4 \%$ spiking levels were within $\pm 20 \%$ relative error. Results for the other three analytes, $C_{14: 0}$, $\mathrm{C}_{17: 0}$, and $\mathrm{C}_{22: 6}$ remained within $\pm 20 \%$ relative error for all time periods up to 26 weeks. Based on the results, it can be stated that $C_{18: 0}$ is stable for up to 8 weeks, and $\mathrm{C}_{14: 0}, \mathrm{C}_{17: 0}$, and $\mathrm{C}_{22: 6}$ are stable for up to 26 weeks of frozen storage. See Table 8.

Table 7. Short-term stability $(2,24,48$ hour) of four fatty acids (\% recoveries $[ \pm R E \%])$ in whole chicken egg extracts spiked $(0.1 \%, 0.25 \%$ and $0.4 \% \mu \mathrm{g} / \mathrm{ml} ; \mathrm{n}=3)$ with mixed FAME standard solution.

\begin{tabular}{|c|c|c|c|}
\hline \multirow{2}{*}{ Fatty Acid ID } & \multicolumn{3}{|c|}{$\underline{\text { Recoveries }(\%) \text { at } 0.1 \% \text { Spiking Level }( \pm \mathrm{RE} \%)}$} \\
\hline & 2 -hour Mean $(\mathrm{n}=3)$ & 24 -hour Mean $(\mathrm{n}=3)$ & 48-hour Mean $(n=3)$ \\
\hline $\mathrm{C}_{14: 0}$ & 107.7 & $108(0.3)$ & $110(2.2)$ \\
\hline $\mathrm{C}_{17: 0}$ & 107.7 & $109(1.2)$ & $110(2.2)$ \\
\hline $\mathrm{C}_{18: 0}$ & 109 & $106(-2.8)$ & $102(-6.4)$ \\
\hline $\mathrm{C}_{22: 6}$ & 106.7 & $106.3(-0.3)$ & $107.7(0.9)$ \\
\hline \multirow{2}{*}{ Fatty Acid ID } & \multicolumn{3}{|c|}{ Recoveries (\%) at $0.25 \%$ Spiking Level (RE\%) } \\
\hline & Mean & Mean & Mean \\
\hline $\mathrm{C}_{14: 0}$ & 107.7 & $109.3(1.5)$ & $109(1.2)$ \\
\hline $\mathrm{C}_{17: 0}$ & 107.3 & $109.7(2.2)$ & $109.7(2.2)$ \\
\hline $\mathrm{C}_{18: 0}$ & 105.3 & $107(1.6)$ & $100.7(-4.4)$ \\
\hline $\mathrm{C}_{22: 6}$ & 105.7 & $108.7(2.8)$ & $107.7(1.9)$ \\
\hline \multirow{2}{*}{ Fatty Acid ID } & \multicolumn{3}{|c|}{$\underline{\text { Recoveries (\%) at } 0.4 \% \text { Spiking Level (RE\%) }}$} \\
\hline & Mean & Mean & Mean \\
\hline $\mathrm{C}_{14: 0}$ & 107.3 & $108.3(0.9)$ & $108.3(0.9)$ \\
\hline $\mathrm{C}_{17: 0}$ & 105.7 & $107.7(1.9)$ & $108(2.2)$ \\
\hline $\mathrm{C}_{18: 0}$ & 102 & $101.7(-0.3)$ & $102(0)$ \\
\hline $\mathrm{C}_{22: 6}$ & 103.3 & $104.3(1.0)$ & $106.3(2.9)$ \\
\hline
\end{tabular}

Where: $R E \%($ Relative Error \% $)=\left[\left(X_{t}-X_{t 0}\right) / X_{t 0}\right] * 100$. 


\subsubsection{Freeze and Thaw}

The freeze and thaw process consisted of repeated analysis of egg samples over the course of four freeze and thaw cycles. Freezing was established at $\leq-16^{\circ} \mathrm{C}$ overnight and thawing took place at room temperature for more than two hours. Initial analysis after one freeze-thaw cycle established the baseline measurement. Sample aliquots were tested after each freeze-thaw cycle for four cycles. The results after each freeze-thaw cycle compared to extracts from initial extraction ( $\mathrm{T}$ $=0$ (cycle 1)) for the parameters monitored: $\mathrm{C}_{14: 0}, \mathrm{C}_{17: 0}, \mathrm{C}_{18: 0}$ and $\mathrm{C}_{22: 6}$ ranged from $-9.6 \%$ to $0.8 \%$, within the acceptable range of $\pm 20 \%$ relative error. The analytes were deemed to be stable over four freeze and thaw cycles (Table 9).

Table 8. Long-term (26 week) stability of four fatty acids (\% recoveries $[ \pm \mathrm{RE} \%$ compared to Time 0]) in whole chicken egg extracts spiked $(0.1 \%, 0.25 \%$ and $0.4 \% \mu \mathrm{g} / \mathrm{ml} ; \mathrm{n}=3$ ) with mixed FAME standard solution.

\begin{tabular}{cccccccc}
\hline \multicolumn{7}{c}{ Percent Recoveries at 0.1\% Spiking Level Mean (n =3) } \\
\hline \multirow{7}{*}{ Fatty Acid ID } & \multicolumn{7}{c}{ Time (weeks) } \\
\cline { 2 - 8 } & 0 & 4 & 8 & 12 & 16 & 20 & 26 \\
\hline $\mathrm{C}_{14: 0}$ & 88.3 & $88.0(-0.4)$ & $86.7(-1.9)$ & $83.0(-6.0)$ & $85.3(-3.4)$ & $84.3(-4.5)$ & $86.3(-2.3)$ \\
$\mathrm{C}_{17: 0}$ & 106.7 & $107.7(0.9)$ & $102(-4.4)$ & $96.7(-9.4)$ & $99.0(-7.2)$ & $98(-8.1)$ & $97.3(-8.8)$ \\
$\mathrm{C}_{18: 0}$ & 89.7 & $91.3(1.9)$ & $88.0(-1.9)$ & $57.3(-36)$ & $69.0(-23)$ & $57.3(-36)$ & $65.3(-27)$ \\
$\mathrm{C}_{22: 6}$ & 98.3 & $105.0(6.8)$ & $94.7(-3.7)$ & $88.0(-11)$ & $93.0(-5.4)$ & $89.3(-9.2)$ & $99.0(0.7)$ \\
\hline \multicolumn{7}{c}{ Percent Recoveries at 0.25\% Spiking Level Mean (n=3) } \\
\hline $\mathrm{C}_{14: 0}$ & 90.3 & $89.0(-1.5)$ & $88.0(-2.6)$ & $83.7(-7.4)$ & $91.0(0.7)$ & $89.0(-1.5)$ & $89.3(-1.1)$ \\
$\mathrm{C}_{17: 0}$ & 104.0 & $102.7(-1.3)$ & $99.0(-4.8)$ & $93.3(-10)$ & $100.7(-3.2)$ & $98.0(-5.8)$ & $97.3(-6.4)$ \\
$\mathrm{C}_{18: 0}$ & 92.3 & $84.0(-9)$ & $87.7(-5.1)$ & $68.7(-26)$ & $89.3(-3.2)$ & $80.7(-13)$ & $81.7(-12)$ \\
$\mathrm{C}_{22: 6}$ & 97.7 & $99.3(1.7)$ & $83.3(-15)$ & $89.3(-8.5)$ & $98.3(0.7)$ & $94.7(-3.1)$ & $99.7(2)$ \\
\hline \multicolumn{7}{c}{ Percent Recoveries at 0.4\% Spiking Level Mean (n=3) } \\
\hline $\mathrm{C}_{14: 0}$ & 87 & $88(1)$ & $83(-5)$ & $82(-6.1)$ & $88(0.8)$ & $85.3(-2.3)$ & $87(-0.4)$ \\
$\mathrm{C}_{17: 0}$ & 100 & $103(3)$ & $91(-9)$ & $90.3(-9.7)$ & $97(-3)$ & $93(-7)$ & $93.7(-6.3)$ \\
$\mathrm{C}_{18: 0}$ & 92 & $95(4)$ & $77(-17)$ & $74(-20)$ & $89.7(-2.5)$ & $80.3(-13)$ & $81.3(-12)$ \\
$\mathrm{C}_{22: 6}$ & 96 & $102(7)$ & $77(-20)$ & $87.3(-8.7)$ & $96(0.3)$ & $91(-4.9)$ & $97.3(1.7)$ \\
\hline
\end{tabular}

Table 9. Freeze and Thaw Stability (four cycles) of four fatty acids in chicken egg extract at a spiked concentration of $3000 \mu \mathrm{g} / \mathrm{ml}$.

\begin{tabular}{|c|c|c|c|c|c|c|c|c|c|c|c|c|}
\hline \multirow{2}{*}{$\begin{array}{l}\text { Fatty } \\
\text { acid }\end{array}$} & \multicolumn{5}{|c|}{ Amount Found $(\mu \mathrm{g} / \mathrm{ml})$} & \multicolumn{4}{|c|}{ Recoveries (\%) } & \multicolumn{3}{|c|}{$\begin{array}{l}\text { Relative Error (\%) } \\
\text { compared to FTC } 1\end{array}$} \\
\hline & Blank & FTC-1 & FTC-2 & FTC-3 & FTC-4 & FTC-1 & FTC-2 & FTC-3 & FTC-4 & FTC-2 & FTC-3 & FTC-4 \\
\hline $\mathrm{C}_{14: 0}$ & 202.9 & 3474.6 & 3503.0 & 3426.3 & 3215.5 & 109 & 110 & 107 & 100 & 0.8 & -1.5 & -7.9 \\
\hline $\mathrm{C}_{17: 0}$ & 181.8 & 3487.7 & 3493.8 & 3424.3 & 3204.6 & 110 & 110 & 108 & 101 & 0.1 & -1.9 & -8.6 \\
\hline $\mathrm{C}_{18: 0}$ & 6225.6 & 9502.7 & 9358.7 & 9430.7 & 9147.5 & 109 & 104 & 107 & 99 & -5.0 & -2.0 & -9.6 \\
\hline $\mathrm{C}_{22: 6}$ & 1039.7 & 4233.3 & 4201.5 & 4190.7 & 3955.8 & 106 & 105 & 105 & 97 & -1.1 & -1.5 & -8.5 \\
\hline
\end{tabular}

FTC: Freeze thaw cycle number. 


\section{Conclusion}

Considering that whole egg is frequently consumed, either as a stand-alone food item in the diet or in the formulation of a variety of food products, with the growing trend in omega-3 biofortification through the chicken's diet, the establishment of an accurate quantification assay for the determination of the fatty acid composition is important for nutritionists and regulatory scientists. From the results of our study, the suitability of the AOAC method 996.06 for the determination of DHA $\left(\mathrm{C}_{22: 6}\right)$ and three additional fatty acids $\left(\mathrm{C}_{14: 0}, \mathrm{C}_{17: 0}\right.$ and $\left.\mathrm{C}_{18: 0}\right)$ was established for an individual whole chicken egg. The method was verified for use by examining the method parameters, linearity, accuracy and precision, specificity and by determining the LOD and LOQ for each analyte. The results of the accuracy and precision experiments were within acceptable limits for the individual whole chicken egg matrix, along with robustness of the method confirmed through limited variability of the analysis precision and accuracy when investigated by a second analyst. The measured fatty acid components of the egg products showed good stability when subjected to 4 freeze-thaw challenge cycles and DHA was stable when stored for up to 26 weeks at $-20^{\circ} \mathrm{C}$.

\section{Acknowledgements}

Experimental analyses were performed by Huey Kuan, Gloria Wang, Yuki Nakagawa of Merieux NutriSciences (Burnaby). The authors would like to express their gratitude to Ms. Rebecca Timmons (Alltech USA) for her technical input.

\section{Declaration of Conflicting Interests}

The funders had no role in the design of the study; in the collection, analyses, or the interpretation of data. GD, AY and CM work for Alltech, who sponsored the research, contributed to the writing of the manuscript and in the decision to publish the results.

\section{Conflicts of interest}

The authors declare that there is no conflict of interest regarding the publication of this paper.

\section{References}

[1] Swanson, D., Block, R. and Mousa, S.A. (2012) Omega-3 Fatty Acids EPA and DHA: Health Benefits throughout Life. Advances in Nutrition, 3, 1-7. https://doi.org/10.3945/an.111.000893

[2] Grosso, G., Pajak, A., Marventano, S., Castellano, S., Galvano, F., Bucolo, C., Caraci, F., et al. (2014) Role of Omega-3 Fatty Acids in the Treatment of Depressive Disorders: A Comprehensive Meta-Analysis of Randomized Clinical Trials. PLoS ONE, 9 , e96905. https://doi.org/10.1371/journal.pone.0096905

[3] Calder, P.C. (2015) Marine Omega-3 Fatty Acids and Inflammatory Processes: Effects, Mechanisms and Clinical Relevance. Biochimica et Biophysica Acta 
(BBA)-Molecular and Cell Biology of Lipids, 1851, 469-484. https://doi.org/10.1016/j.bbalip.2014.08.010

[4] Deckelbaum, R.J. and Torrejon, C. (2012) The Omega-3 Fatty Acid Nutritional Landscape: Health Benefits and Sources. The Journal of Nutrition, 142, 587S-591S. https://doi.org/10.3945/jn.111.148080

[5] Meyer, B.J., Mann, N.J., Lewis, J.L., Milligan, G.C., Sinclair, A.J. and Howe, P.R. (2003) Dietary Intakes and Food Sources of Omega-6 and Omega-3 Polyunsaturated Fatty Acids. Lipids, 38, 391-398. https://doi.org/10.1007/s11745-003-1074-0

[6] Meyer, B. (2011) Are We Consuming Enough Long Chain Omega-3 Polyunsaturated Fatty Acids for Optimal Health? Prostaglandins, Leukotrienes and Essential Fatty Acids (PLEFA), 85, 275-280. https://doi.org/10.1016/j.plefa.2011.04.010

[7] EFSA Panel on Dietetic Products, N. and Allergies (2010) Scientific Opinion on Dietary Reference Values for Fats, Including Saturated Fatty Acids, Polyunsaturated Fatty Acids, Monounsaturated Fatty Acids, Trans Fatty Acids, and Cholesterol. EFSA Journal, 8, 1461. https://doi.org/10.2903/j.efsa.2010.1461

[8] Sheppard, K.W. and Cheatham, C.L. (2018) Omega-6/Omega-3 Fatty Acid Intake of Children and Older Adults in the US: Dietary Intake in Comparison to Current Dietary Recommendations and the Healthy Eating Index. Lipids in Health and Disease, 17, 43. https://doi.org/10.1186/s12944-018-0693-9

[9] Stark, K.D., Van Elswyk, M.E., Higgins, M.R., Weatherford, C.A. and Salem Jr., N. (2016) Global Survey of the Omega-3 Fatty Acids, Docosahexaenoic Acid and Eicosapentaenoic Acid in the Blood Stream of Healthy Adults. Progress in Lipid Research, 63, 132-152. https://doi.org/10.1016/j.plipres.2016.05.001

[10] Rymer, C. and Givens, D. (2005) n-3 Fatty Acid Enrichment of Edible Tissue of Poultry: A Review. Lipids, 40, 121-130. https://doi.org/10.1007/s11745-005-1366-4

[11] Moran, C., Morlacchini, M., Keegan, J. and Fusconi, G. (2018) Increasing the Omega-3 Content of Hen's Eggs through Dietary Supplementation with Aurantiochytrium limacinum Microalgae: Effect of Inclusion Rate on the Temporal Pattern of Docosahexaenoic Acid Enrichment, Efficiency of Transfer, and Egg Characteristics. The Journal of Applied Poultry Research, pfy075. https://doi.org/10.3382/japr/pfy075

[12] Keegan, J.D., Currie, D., Knox, A. and Moran, C.A. (2019) Redressing the Balance: Including DHA-Rich Aurantiochytrium Limacinum in Broiler Diets Increases Tissue Omega-3 Fatty Acid Content and Lowers the n-6: n-3 Ratio. British Poultry Science. (In Press) https://doi.org/10.1080/00071668.2019.1605153

[13] Konieczka, P., Barszcz, M., Choct, M. and Smulikowska, S. (2017) The Interactive Effect of Dietary n-6: n-3 Fatty Acid Ratio and Vitamin E Level on Tissue Lipid Peroxidation, DNA Damage in Intestinal Epithelial Cells, and Gut Morphology in Chickens of Different Ages. Poultry Science, 97, 149-158.

https://doi.org/10.3382/ps/pex274

[14] Moran, C.A., Keegan, J.D., Vienola, K. and Apajalahti, J. (2018) Broiler Tissue Enrichment with Docosahexaenoic Acid (DHA) through Dietary Supplementation with Aurantiochytrium Limacinum Algae. Food and Nutrition, 9, 1160-1173. https://doi.org/10.4236/fns.2018.910084

[15] Folch, J., Lees, M. and Sloane Stanley, G. (1957) A Simple Method for the Isolation and Purification of Total Lipides from Animal Tissues. Journal of Biological Chemistry, 226, 497-509.

[16] Gaffney, M., O’Rourke, R., Taylor-Pickard, J. and Murphy, R. (2015) A Comparative Assessment of the Fatty Acid Profiles and Antioxidant Status of Supermarket 
Eggs. Journal of Applied Animal Nutrition, 3, e9.

https://doi.org/10.1017/jan.2015.7

[17] Payet, M., Esmail, M.H., Polichetti, E., Le Brun, G., Adjemout, L., Donnarel, G., Pieroni, G., et al. (2004) Docosahexaenoic Acid-Enriched Egg Consumption Induces Accretion of Arachidonic Acid in Erythrocytes of Elderly Patients. British Journal of Nutrition, 91, 789-796. https://doi.org/10.1079/BJN20041106

[18] Mazalli, M.R. and Bragagnolo, N. (2007) Validation of Two Methods for Fatty Acids Analysis in Eggs. Lipids, 42, 483-490. https://doi.org/10.1007/s11745-007-3046-4

[19] Dillon, G.P., Yiannikouris, A., Brandl, W., Cardinall, C., Yuan, W. and Moran, C.A. (2019) Fitness for Purpose and Stability Assessment of Long-Chain Polyunsaturated Fatty Acids in Chicken Tissues. Regulatory Toxicology and Pharmacology, 103, 93-99. https://doi.org/10.1016/j.yrtph.2019.01.014

\section{Abbreviations}

DHA = Docosahexaenoic Acid

$\mathrm{EPA}=$ Eicosapentaenoic acid

FID = Flame Ionization Detector

$\mathrm{GC}=$ Gas Chromatography

HPLC $=$ High Performance Liquid Chromatography

IS $=$ Internal Standard

$\mathrm{LA}=$ Linoleic Acid

LC-PUFA = Long Chain Poly Unsaturated Fatty Acids

LOD $=$ Limit of Detection

LOQ = Limit of Quantitation 